\title{
Public Perceptions of a New MRT Service: a Pre-launch Study in Jakarta
}

\author{
Ahmad Faisal Dahlan ${ }^{1} \cdot$ Anna Fraszczyk ${ }^{1}$
}

Received: 20 June 2019/Revised: 12 October 2019/Accepted: 24 October 2019/Published online: 8 November 2019

(C) The Author(s) 2019

\begin{abstract}
Jakarta Mass Rapid Transit (MRT) is the first rapid transit system in Indonesia, built with the aim of alleviating the severe congestion in Jakarta by offering a travel alternative to people using private vehicles. Although Jakarta MRT is the most sophisticated inland transport mode in Jakarta, prior to its launch, there was no evidence or guarantee that the local community was willing to use it. Hence, the pre-launch study of a non-operational public transport system was introduced to better understand perceptions of the new MRT service in Jakarta from its potential future customers' perspective as well as their willingness to use it. A survey was conducted on 516 respondents in Jakarta and three surrounding areas of Depok, Tangerang, and Bekasi. The collected data was divided into two respondent groups: 'MRT corridor areas' (the MRT group), which includes Central and South Jakarta residents, and 'other areas' (the other group), which includes residents from all the other surrounding areas. The key finding of the study is that a great majority of the respondents from both groups declared a willingness to undertake a mode shift to Jakarta MRT services in the future. Various statistically significant differences were identified between the two groups. Moreover, respondents ranked six factors in the order of priority when selecting a transport mode, with reliability and safety issues identified as the most important. A set of key recommendations, addressed to the Jakarta MRT operator, is listed in order to optimize the MRT's role in alleviating congestion in Jakarta. The study approach presented in this
\end{abstract}

\footnotetext{
Ahmad Faisal Dahlan

fais.dahl@gmail.com

1 Mahidol University, Nakhon Pathom, Thailand
}

Communicated by Marin Marinov. paper could be applied by other cities considering introduction of a new (transport or) metro system in order to understand its potential customers' perceptions and expectations toward the new service.

Keywords Jakarta MRT · Public perception · Metro · Survey

\section{Introduction}

Jakarta, the capital city of Indonesia, has been classified as a megacity since 2014 with a population of over 10 million people [1]. A majority of Jakarta citizens tends to own private vehicles, and in 2013, there were nearly 12 million motorcycles and over 3 million private cars registered in the city in comparison to 360,000 public buses [2]. Public transport, due to its poor quality and unpredictable travel time, has not been able to compete effectively with private vehicles [3]. As a consequence, the city has been experiencing high traffic congestion levels for years, which affect citizens and the city at many levels, from the environment to health to the economy. The local government of Jakarta has struggled to combat the traffic congestion issue for years and has provided several public transport and policy solutions, from Bus Rapid Transit (BRT) and Light Rail Transit (LRT), to the odd/even policy for private cars, and the working and school hours regulation [4]. However, since these measures still did not solve the problem of congestion in the city, another solution was proposed. In 2005, the development of Jakarta Mass Rapid Transit (MRT) was approved [5]. The MRT was expected to reduce the volume of private transport, which operates on the roads of Jakarta [6-8]. The first phase of Jakarta MRT, officially launched in March 2019, connected the Lebak 
Bulus station in South Jakarta to the Bundaran Hotel Indonesia station in Central Jakarta. The MRT was built to support government programs in reducing congestion and air pollution levels, revitalizing areas along the MRT route, and improving regional and national economies [5].

As literature shows, the volume of public transport research is growing in Indonesia. These studies often focus on the evaluation of existing bus or paratransit services in order to highlight necessary improvements and suggest recommendations to operators, government and other stakeholders. Although feasibility studies were conducted to prove the case of MRT in Jakarta [9], no studies were found to investigate people's perception of the new MRT service or their willingness to use it in the future. These soft aspects of travel behaviour and mode shift are often neglected in early stages of a new metro project implementation and this, in combination with other factors, can contribute to overestimation of traffic demand [10]. It is recognised that a study focused on public perception of a new MRT service in Jakarta would allow us to underst and the expectations of MRT's future customers better as well as adjust the system to better meet their needs. Therefore, this paper presents the results of a study conducted in Jakarta before the launch of MRT service. It analyses a sample of Jakarta residents' and their views regarding the new service as seen from the perspectives of residents living in two areas: the MRT corridor versus other areas. The aim of the paper is to create new knowledge about Jakarta respondents' expectations of the new MRT service and their pre-launch willingness to use it as well as to contribute to the volume of literature about public transport research in Indonesia.

The paper is organised as follows. A background of the study is explained in Sect. 2, where examples of research focused on existing public transport in Indonesia as well as prelaunch public transport services are evaluated and a research gap is stated. Next, Sect. 3 presents the methodology applied in the study, including a questionnaire design and data collection. Section 4 focuses on the presentation of analysis of results, where the sample of 516 respondents is divided into two subgroups based on their location either along the MRT corridor or in other areas of the megacity. Section 5 offers discussion on the results, and Sect. 6 presents the conclusions and recommendations to stakeholders. Finally, Sect. 7 lists the limitations of the study, and Sect. 8 offers possible future research directions.

\section{Background}

\subsection{Evaluation of Existing Public Transport Services in Indonesia}

The literature is rich in publications focused on public perception of transport, and these studies were generally conducted to evaluate existing public transport systems [11-16]. The voices of potential passengers appeared to be, more or less, important in developing the existing systems.

Munawar [12] conducted a research on people's perception of a bus system in Jogjakarta, Indonesia. The survey was employed to collect data from 300 respondents, and analysis of results showed that one of the key reasons why respondents do not use public busses was due to their slow speed. The bus speed, and some other specific issues highlighted by the bus users, were then put into a list of recommendations addressed to the bus operator in order to attract more potential users of their service in the future. A similar study, but focused on paratransit's characteristics, was conducted by Joewono et al. [17]. They collected data from three metropolitan areas: Jakarta, Bandung, and Yogyakarta, analysed it, and concluded that respondents expected paratransit to improve in the three key areas of: service quality, security, and shelter options.

Purba et al. [14] evaluated the service quality of Trans Jogja as a transit system in Jogjakarta. Eight service characteristics, such as route, service, reliability, information, comfort, safety and security, fare, and environment, were included in the study. The environment aspect covered an emissions issue, which was caused by Trans Jogja. The study involved 246 respondents, who were asked questions through a face-to-face interview. The Heterogeneous Customer Satisfaction Index (HCSI) was employed to evaluate the service quality of Trans Jogja. Overall, the score for HCSI was 7.22 out of 10 , which meant that $72 \%$ of the customers were satisfied with the service delivered. Yet, it was recognised that still a lot of effort was required in order to increase the customers' satisfaction of Trans Jogja to a higher level. The image of public transport was also investigated in another study by Sumaedi et al. [18], where they studied factors that could affect public transport users' intentions to reuse public transport. Several factors, including attitude, subjective norm, perceived behavioural control (PBC), perceived value, and image, were involved in the study. The questionnaire was distributed to 293 public transport users in Tangerang. The results indicated that public transport users' intentions to reuse public transport could be affected by attitude, subjective norm, and image. Yet, perceived value and PBC did not influence public transport passengers' intention to reuse significantly.

Sumaedi et al. [19] examined the effect of passengers' satisfaction when viewed from perceived value, image, perceived ease of use, and perceived usefulness. The survey was distributed to 292 public transport users in Jakarta, Indonesia. The results indicated that perceived value, perceived usefulness, and image could influence public transport users, while perceived ease did not influence the satisfaction. Nelloh et al. [20] tested travel experience on travel satisfaction and loyalty of BRT users in Jakarta. The 
study employed a structure equation model (SEM) to reveal the relationship between travel experience variables with travel satisfaction and loyalty. The results indicated that individual space, staff's skills, vehicle maintenance, and ticket line service had a positive effect on travel satisfaction. Then, the travel satisfaction had a positive influence on customer loyalty. Still, in Jakarta, Herdiansyah et al. [21] attempted to seek factors that influence factory employees in choosing public transport (BRT, bus, and train). This research was a response to relatively low use of public transport or only $24 \%$ of road users from a total of 47.5 million trips in Jakarta and surrounding areas in 2015. The results indicated that the number of factory employees who choose public transport was still low. Nevertheless, the employees indicated such a great potential to shift to public transport as long as the local government showed commitment to fixing public transport.

Rapid information technology development has triggered online transport modes. Some studies were attempted to assess online transport modes. Widjaja et al. [22] focused on assessing customer satisfaction and loyalty. Partial least square (PLS) and importance-performance analysis (IPA) were employed to analyse the data. The data was obtained from 200 respondents. The results indicated that $48.67 \%$ of the respondents were satisfied and chose to be loyal to the online modes, where alternative transport in handling congestion, safety, and fast safe indicators were the greatest indicators for both customer satisfaction and loyalty, respectively. On a bigger spectrum, Meldayani et al. [23] conducted similar study, but involved service quality, price, location, loyalty, and product design in assessing customer satisfaction of online motorcycle transport service. Two hundred and ninety-nine millennial respondents domiciled in Jakarta were asked to fill out the survey. The results showed that there was a significant influence of the aforementioned indicators on the customer satisfaction levels.

A different transport research perspective was presented by Belgiawan et al. [24], who conducted a study about intention of owning a car among students in Bandung. The authors wanted to investigate the reasons behind the desire to own a car, which could help to put the public transport offer in a different context. The study involved 500 undergraduate students from one university in Bandung, and the outcome showed that the three key variables of independence, arrogant prestige, and some socio-demographics significantly influenced the intention of owning a car.

Overall, there has been a wide variety of public transport studies conducted in different cities across Indonesia. A majority of them look at existing transport systems, evaluate them, and recommend ways operators could improve these services. No studies were found to deal with pre- launch expectations of a new public transport service in Indonesia. Also, no research studies were found to look at MRT as a new public transport option.

\subsection{Pre-launch Perception of Public Transport Services}

Another approach to public perception study would be to run it before a new transport system is in operation. Such a pre-launch study could emphasise what potential passengers think about the new public transport system and what factors and features they recommend for improvement, based on their perceptions of the new service. Results of such a study could form important findings for the public transport operator and serve as a foundation for further research.

Few examples of pre-launch studies were found to look at new or proposed railways. For instance, Fraszczyk and Mulley [25] carried out research on public perception of an automated metro system in Sydney, Australia. They investigated what Sydney-siders think about the new driverless train. The study was arranged in 2017, well before the automated metro system launch planned for mid-2019. The study allowed understanding of the public's perspective better (e.g. views on safety), identified ways to overcome some challenges with the public's perception of the system, and gave recommendations to stakeholders on how to handle these (e.g. diverse marketing approach).

Danapour et al. [26] conducted public perception research about high-speed rail (HSR) in comparison with air transport (AT) in Iran. They examined how competitive the planned HSR is based on five variables: ticket price, travel time, hospitality, and convenience. The results showed that HSR could compete with AT. Another study from the UK looked at public attitudes to and perception of a planned high-speed rail (HSR) service [27]. The authors collected 1799 responses, and analysis identified fix factors that played a role in people's responses: travel security, improvement to road and air, prestige of HSR, comfort, negative aspects of HSR, and the usefulness of travel time. Moreover, significant differences across the factors were found in terms of respondents' demographic as well as their travel characteristic. For example, women's scores for travel security concerns were higher than those of men or respondents with the most positive attitudes towards HSR expressed a greater willingness to pay for travel time savings.

\subsection{Jakarta MRT Phase 1}

Jakarta MRT has been built by PT. MRT Jakarta since October 2013, following share ownership of $99.98 \%$ by the local government of DKI Jakarta and $0.002 \%$ by PD Pasar 
[28]. The aim of the MRT is to support both local and national economies, reduce the traffic congestion and pollution, and also revitalise areas along the MRT route by providing adequate infrastructure [5].

The construction of Jakarta MRT phase 1 started on 10 October 2013 [28] and this includes the route from the Lebak Bulus station to the Bundaran Hotel Indonesia station, which is $16 \mathrm{~km}$ long. The construction has already been completed, and operations were launched in March 2019. Phase 1 provides a double-track route (north-south corridor; Fig. 1) with 13 stations and one depot. The local government plans to continue phase 2 of the MRT construction after completion of phase 1 . The second phase of the MRT line is planned from west to east of Jakarta.

A feasibility study was conducted to understand the need for Jakarta MRT and benefits it will bring to the city. The document included information about passenger demand profiles, and environmental and financial aspects. However, no other studies were identified to deal with Jakarta MRT, especially from potential users' perspective. Literature shows that there are very few studies published looking at pre-launch perception of a transport service by

\section{The Jakarta MRT Corridor}

\section{LEGEND}

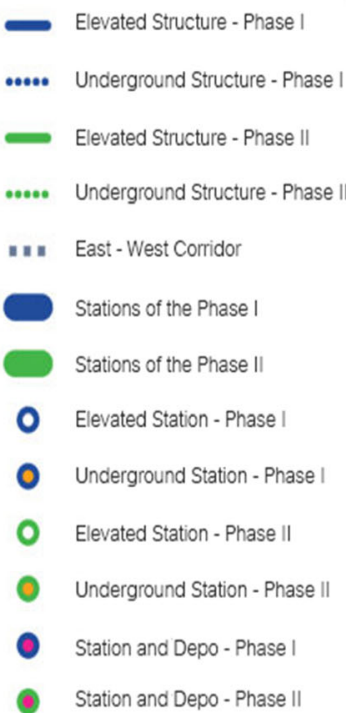

\section{North Jakarta} Tangerang: Balarala

i.

i. Harmorl

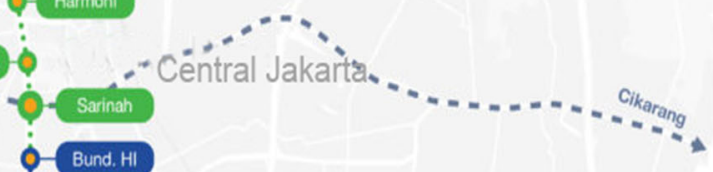

West Jakarta

(1)

Statabuit 9 Jakarta

$\circ$ Bentit

0 Senvan

East Jakarta

Fig. 1 Jakarta MRT's corridor (edited from PT. MRT Jakarta [28]) 
its potential users. However, new knowledge and direction these studies could offer should be of interest to decisionmakers and new public transport operators as it would allow them to tailor their new marketing strategies better and adjust their services to the expectations of their potential customers.

\subsection{Research Gap}

To date, a great majority of public perception research on transport services in Indonesia involves existing systems. This is well understood as this kind of research evaluates the existing systems and their performance so that they could be improved in the future. However, the pre-launch study of a non-operational public transport system could also be useful in order to establish potential challenges with people's perceptions of and attitudes towards the new system.

The Jakarta MRT pre-launch case study offered a unique research opportunity to investigate people's perceptions of the new service and their readiness to welcome a modern public transport in the city. As it was the first study of this kind in Indonesia, it was also seen as a foundation for the future development of the MRT in the country. Hence, the concept of this study was to comprehend the views of Jakarta residents about Jakarta MRT, prior to its expected launch in March 2019.

\section{Methodology}

\subsection{Questionnaire Design}

A questionnaire was designed to accommodate perceptions of Jakarta residents towards the new MRT service. The key information that would be explored in this questionnaire was the willingness to use the MRT and expectations from its development.

As several other studies showed, respondents' views about a transport system as well as their travel choices could be influenced by their socio-demographic characteristics and their travel behaviour [29]; therefore, a similar strategy was applied in this study. The questionnaire was divided into three sections: one on socio-demographics; one on travel behaviour; and one on views of Jakarta MRT. The survey was originally designed in English and then translated into Indonesian language, which was used in the data-collection process.

Section 1 of the questionnaire investigated socio-demographic characteristics of the respondents and consisted of five questions, such as: location, gender, age, occupation, and income. Section 2 of the questionnaire was focused on travel behaviour and investigated travel tools and habits, such as: vehicle ownership or type of transport mode used for commuting. This section was based on several other transport studies, which involved travel behaviour aspects, as they could link to travel preferences in the future [12, 17, 30-32]. Both sections, socio-demographics and travel behaviour, were crucial to providing detailed information about respondents involved in the study.

Section 3 of the questionnaire included questions related to respondents' view of Jakarta MRT: willingness to use the MRT and expectations of the MRT system prior to its launch. The willingness questions were expected to help with understanding of the MRT demand in the future. Jain et al. [31] used this type of question to reveal whether the respondents were willing to shift to public transport, while Munawar [12] explored respondents' expectations about public transport in Yogyakarta, Indonesia. In the expectation questions, the respondents are presented with six factors, which aim to look at their importance for future MRT development.

\subsection{Data Collection}

As the population of Jakarta is over 10 million people, a representative sample size needed for the study was calculated. It was found that 385 respondents would allow for calculation of results with $95 \%$ confidence interval. The target population of the study included Jakarta, Depok, Tangerang, and Bekasi residents. Even though phase 1 of Jakarta MRT is geographically located in South and Central Jakarta (see Fig. 1), there was still possibility that other areas' residents were willing to use the MRT in the future. Stratified random sampling was employed to distribute the sample size into eight regencies, as shown in Table 1. This method could increase the accuracy of the sampling, because each stratum represents its own group [33].

An online approach was utilised to collect the data since a majority of the total population in Indonesia are Internet users [34]. The data-collection process was undertaken from 1 February to 7 March 2019. There were three approaches in data collection: (a) personal networking; (b) social media; and (c) online forum discussion. The personal networking approach, where the online questionnaire was distributed to authors' contacts first, allowed for a snowball effect and helped to spread the questionnaire rapidly across different networking groups. The social media approach focused on Facebook groups, where Jakarta and other areas' residents are active. Finally, the survey was also distributed via Kaskus, the biggest online forum in Indonesia, to capture residents of Jakarta not covered in the first two approaches (Table 2).

Overall, the study collected data from 516 respondents. Since the approaches in data collection are likely to incur 
Table 1 Comparison of the sample size planned with the actual data obtained

Table 2 Results of chi-squared test of homogeneity by classification

\begin{tabular}{|c|c|c|c|c|}
\hline Regency & \multicolumn{2}{|c|}{ Sample size planned $(n=385)$} & \multicolumn{2}{|c|}{ Actual data obtained $(n=516)$} \\
\hline North Jakarta & 27 & & 42 & \\
\hline Central Jakarta & 15 & & 45 & \\
\hline East Jakarta & 43 & & 44 & \\
\hline West Jakarta & 38 & & 55 & \\
\hline South Jakarta & 33 & & 90 & \\
\hline Depok & 32 & & 33 & \\
\hline Tangerang & 106 & & 110 & \\
\hline Bekasi & 91 & & 97 & \\
\hline \multirow[t]{2}{*}{ Variables } & & \multicolumn{3}{|l|}{ Classification } \\
\hline & & The MRT group $(n: 135)$ & The other group ( $n: 381)$ & $\chi^{2}$ \\
\hline \multicolumn{5}{|l|}{ Sex } \\
\hline Female & & $78(58 \%)$ & $229(60 \%)$ & .224 \\
\hline Male & & $57(42 \%)$ & $152(40 \%)$ & \\
\hline \multicolumn{5}{|l|}{ Age } \\
\hline $18-25$ & & $55(41 \%)$ & $203(53 \%)$ & 6.679 \\
\hline $26-35$ & & $60(44 \%)$ & $127(33 \%)$ & \\
\hline$\geq 36$ & & $20(15 \%)$ & $51(14 \%)$ & \\
\hline \multicolumn{5}{|l|}{ Occupation } \\
\hline Employee & & $95(70 \%)$ & $226(59 \%)$ & 5.282 \\
\hline Student & & $34(25 \%)$ & $135(35 \%)$ & \\
\hline Unemployed & & $6(5 \%)$ & $20(6 \%)$ & \\
\hline \multicolumn{5}{|l|}{ Income } \\
\hline No income & & $29(22 \%)$ & $139(36 \%)$ & 11.298 \\
\hline Less & & $19(14 \%)$ & $48(13 \%)$ & \\
\hline Average & & $36(27 \%)$ & $81(21 \%)$ & \\
\hline High & & $37(27 \%)$ & $74(20 \%)$ & \\
\hline Very high & & $14(10 \%)$ & $39(10 \%)$ & \\
\hline \multicolumn{5}{|l|}{ Private vehicle } \\
\hline Both & & $22(16 \%)$ & $67(18 \%)$ & .883 \\
\hline Car & & $23(17 \%)$ & $61(16 \%)$ & \\
\hline Motorcycle & & $52(39 \%)$ & $159(42 \%)$ & \\
\hline No & & $38(28 \%)$ & $94(24 \%)$ & \\
\hline \multicolumn{5}{|l|}{ Daily transport mode } \\
\hline Motorcycle & & $42(31 \%)$ & $129(34 \%)$ & 4.851 \\
\hline Car & & $27(20 \%)$ & $64(17 \%)$ & \\
\hline Online ojek & & $23(17 \%)$ & $44(11 \%)$ & \\
\hline BRT & & $6(5 \%)$ & $15(4 \%)$ & \\
\hline BRT; Online ojek & & $9(7 \%)$ & $26(7 \%)$ & \\
\hline Walk & & $6(4 \%)$ & $19(5 \%)$ & \\
\hline Other & & $22(16 \%)$ & $84(22 \%)$ & \\
\hline \multicolumn{5}{|c|}{ MRT's role in alleviating congestion } \\
\hline Important & & $114(84 \%)$ & $348(91 \%)$ & 5.210 \\
\hline I don't know & & $19(14 \%)$ & $29(8 \%)$ & \\
\hline Not important & & $2(2 \%)$ & $4(1 \%)$ & \\
\hline \multicolumn{5}{|c|}{ Willingness to use MRT } \\
\hline Willing & & $101(75 \%)$ & $241(63 \%)$ & 7.397 \\
\hline I don't know & & $33(24 \%)$ & $129(34 \%)$ & \\
\hline Not willing & & $1(1 \%)$ & $11(3 \%)$ & \\
\hline
\end{tabular}


in sampling bias, a chi-squared test of goodness of fit was conducted to analyse it. The test indicates that the location distribution of respondents in the sample is the same as the location distribution of eight regencies, based on the Census: $\chi^{2}(7, N=516)=97.310, p<0.05$. Hence, decision making is binding for the entire population [35].

\section{Results}

\subsection{Socio-demographics and Travel Behaviour}

The dataset was divided into two groups: 'MRT corridor areas' (the MRT group) and 'other areas' (the other group). The MRT group included Central and South Jakarta residents, where the Jakarta MRT corridor was geographically located (sample size of 135), and the other group included residents from all other areas of Jakarta (sample size of 381). The aim of the sample split was to see the effect of location on respondents' views on and decisions regarding the MRT. For the analysis, a chi-squared test of homogeneity is employed to identify the proportion difference among the two groups by independent variables [35]. Then, an independent $t$ test is performed to test whether there is a statistically significant difference between the means in two unrelated groups [35].

Over half of the respondents in both the MRT group and the other group are female (58\% vs. $60 \%$ ), where adults (26-35 years) and young adults (18-25 years) form the largest proportion ( $41 \%$ vs. 53\%). A chi-squared test of homogeneity, as shown in Table 2, confirms that there are significantly more young adults in the other group than in the MRT group: $\chi^{2}(2, N=516)=6.679, p>0.05$. In terms of occupation, most of the respondents in both groups are employed (70\% vs. 59\%). More than half of respondents from the MRT group (64\%) earns salary equal to or greater than the regional minimum wage, where a threshold used for Jakarta is Rp 3,940,972 (an equivalent to 277 USD), in comparison to half of respondents from the other group (51\%). The chi-squared test of homogeneity result shows a statistically significant difference in income among the two groups. The other group's respondents are more likely not to have income, but the MRT groups' respondents appear to be roughly evenly split between average and high income, $\chi^{2}(4, N=516)=11.298$, $p>0.05$.

Both groups have a small proportion of respondents who did not own any private transport ( $28 \%$ vs. $24 \%$ ), and there is no statistically significant difference in private vehicle ownership status between them. This finding confirms that the respondents prefer using a private vehicle, especially a motorcycle (31\% vs. $34 \%$ ), for commuting rather than a public transport option. Another interesting finding is that online ojek, which is an online motorcycle taxi, appears to be a new solution for commuting in short distance. Rapid development of this new transport mode was possible as an alternative to larger vehicles used in severe traffic congestion and because of wide accessibility of the Internet, more specifically, the Internet of Things (IoT).

\subsection{The Respondents' Views of Jakarta MRT}

A great majority of the respondents from both groups (84\% vs. $91 \%$ ) believe that Jakarta MRT plays an important role in relieving congestion in the city; the difference between the two groups is not statistically significant, as Table 2 shows. Furthermore, the development of phase 1 attracts most of the respondents to use it in the future $(75 \%$ vs. $63 \%$ ). Again, the test of homogeneity result shows a statistically significant difference in willingness to use MRT among the two groups. The MRT group respondents are more willing to use MRT in the future, while many of respondents in the other group appear not to be decided yet, $\chi^{2}(2, N=516)=7.397, p>0.05$. Some of these undecided respondents could turn into MRT users in the future and contribute to travel demand increase for this mode, especially in the MRT corridor areas. However, this will depend on the quality of MRT services and various other passengers' requirements. Hence, the expectation section reveals which factors should be highly considered in order to improve the services.

\subsection{The Expectations}

The expectation question consists of six factors: cleanliness, comfort, security, connectivity, reliability, and headway, where the answer options are marked on a 5-point Likert scale (from 1-very negative to 5-very positive). The results show that both groups had very high expectations from the MRT regarding all factors listed, as shown in Fig. 2. Overall, the mean values of results for

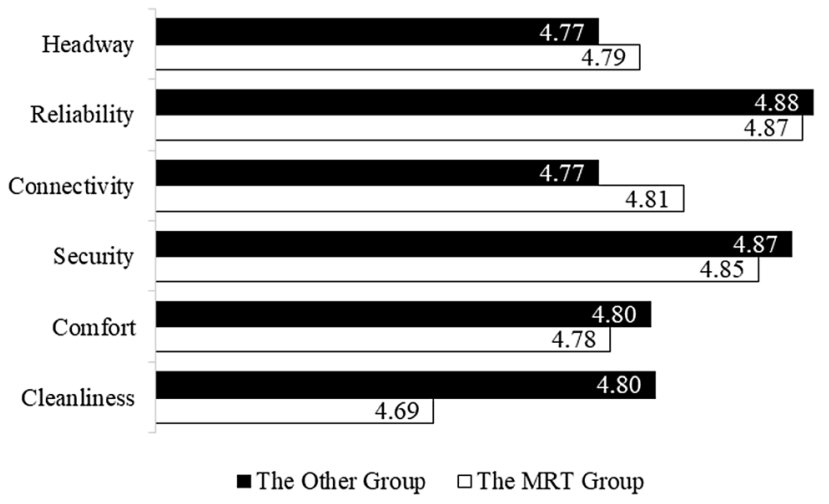

Fig. 2 The expectations (expressed in mean values ranked on a 5-point Likert scale) 
Table 3 Results of $t$ test for the expectation questions by classification

\begin{tabular}{|c|c|c|c|c|c|c|c|c|c|}
\hline & \multicolumn{6}{|c|}{ Classification } & \multirow[t]{3}{*}{$95 \%$ CI for mean difference } & \multirow[t]{3}{*}{$t$} & \multirow[t]{3}{*}{$D f$} \\
\hline & \multicolumn{3}{|c|}{ The MRT group } & \multicolumn{3}{|c|}{ The other group } & & & \\
\hline & $M$ & SD & $N$ & $M$ & SD & $N$ & & & \\
\hline Cleanliness & 4.68 & 0.832 & 135 & 4.80 & 0.625 & 381 & $-0.246,0.023$ & -1.625 & 514 \\
\hline Comfort & 4.77 & 0.594 & 135 & 4.79 & 0.541 & 381 & $-0.129,0.089$ & -0.361 & 514 \\
\hline Security & 4.85 & 0.496 & 135 & 4.86 & 0.468 & 381 & $-0.110,0.076$ & -0.355 & 514 \\
\hline Connectivity & 4.81 & 0.476 & 135 & 4.77 & 0.550 & 381 & $-0.061,0.147$ & 0.810 & 514 \\
\hline Reliability & 4.87 & 0.413 & 135 & 4.87 & 0.454 & 385 & $-0.925,0.082$ & -0.117 & 514 \\
\hline Headway & 4.79 & 0.505 & 135 & 4.77 & 0.613 & 385 & $-0.946,0.136$ & 0.356 & 514 \\
\hline
\end{tabular}

each of the six factors reached 4.69 and over. The aspects of reliability (4.87 for the MRT group vs. 4.88 for the other group) and security (4.85 vs. 4.87 , respectively) score the highest. A paired-samples $t$ test is conducted to compare six factors in the two groups, and results show that there is no significant difference in the score of six factors for the two groups, as shown in Table 3.

\subsection{Willingness to Use Jakarta MRT}

Regression logistics is used to test the strength of the relationship between independent variables and dependent variables, namely, MRT's role and willingness to use MRT. The results show that respondents who do not want to use the MRT in the future tend to disagree that the MRT can reduce congestion in Jakarta by three times, as shown in Table 4. A majority of the respondents in this category is female adult workers who do not own any private vehicle and travel by a motorcycle, a car, or online transport modes to work, as shown in Table 5 . In the willingness category, the respondents who believe that MRT's role is important in alleviating congestion tend to be willing to use the MRT in the future by four times. The distribution of respondents in each variable is evenly distributed, so it is difficult to describe its characteristics. Further, the Hosmer and Lemeshow test is used to see the extent to which a result model is able to explain the data. According to the test, it is recognised that the model is able to explain the data since $p>0.05$.

\section{Discussion}

Phase 1 of Jakarta MRT is built along central business district areas (CBD) from South to Central Jakarta. The single line is expected to accommodate travel patterns of Jakarta and surrounding areas' residents, thus the number of private vehicles might be reduced. The study was conducted before the Jakarta MRT started its operations by asking respondents about their views and expectations for future development of the MRT. For analysis, the data was divided into two location-based groups: the MRT group and the other group. The analysis presented comparative data between the two groups using the chi-squared test as a statistical tool. Further, logistic regression testing was also used to reveal the relationship between dependent variables, which are MRT's role in alleviating congestion and willingness to use the MRT, with independent variables.

The results show that the MRT group's respondents have high income and more desire to use the MRT in comparison to the other group, according to chi-square test of homogeneity. This makes the prospect of the MRT development very positive, especially when targeting South and Central Jakarta residents. Further, the use of online-based transport is now rife because of flexibility and accessibility. In practice, online transport is often a feeder system for BRT in reaching small areas. In the following years, the online transport mode could become a new feeder system for MRT and BRT. Hence, integration of different public transport services (MRT, BRT, and online transport) could become a selling point in providing a flexibility aspect and compete with private vehicles. The results of the logistic regression analysis show that the respondents who do not understand the important role of MRT in alleviating congestion tend not to choose MRT as an option. Therefore, the MRT operator would be advised to actively campaign for the MRT's important role in reducing the level of congestion in Jakarta as well as highlighting other benefits the service brings to the city.

The travel demand from the MRT is expected to increase and gradually reduce the use of private vehicles in Jakarta. To welcome the estimated increase in the number of passengers, the MRT operator should secure excellent service quality so as to increase customer satisfaction. In addition, reliability, security, and connectivity are very important factors to consider, and these are followed closely by comfort, headway, and cleanliness. 
Table 4 Logistic regression analysis of MRT's role in alleviating congestion and willingness to use MRT

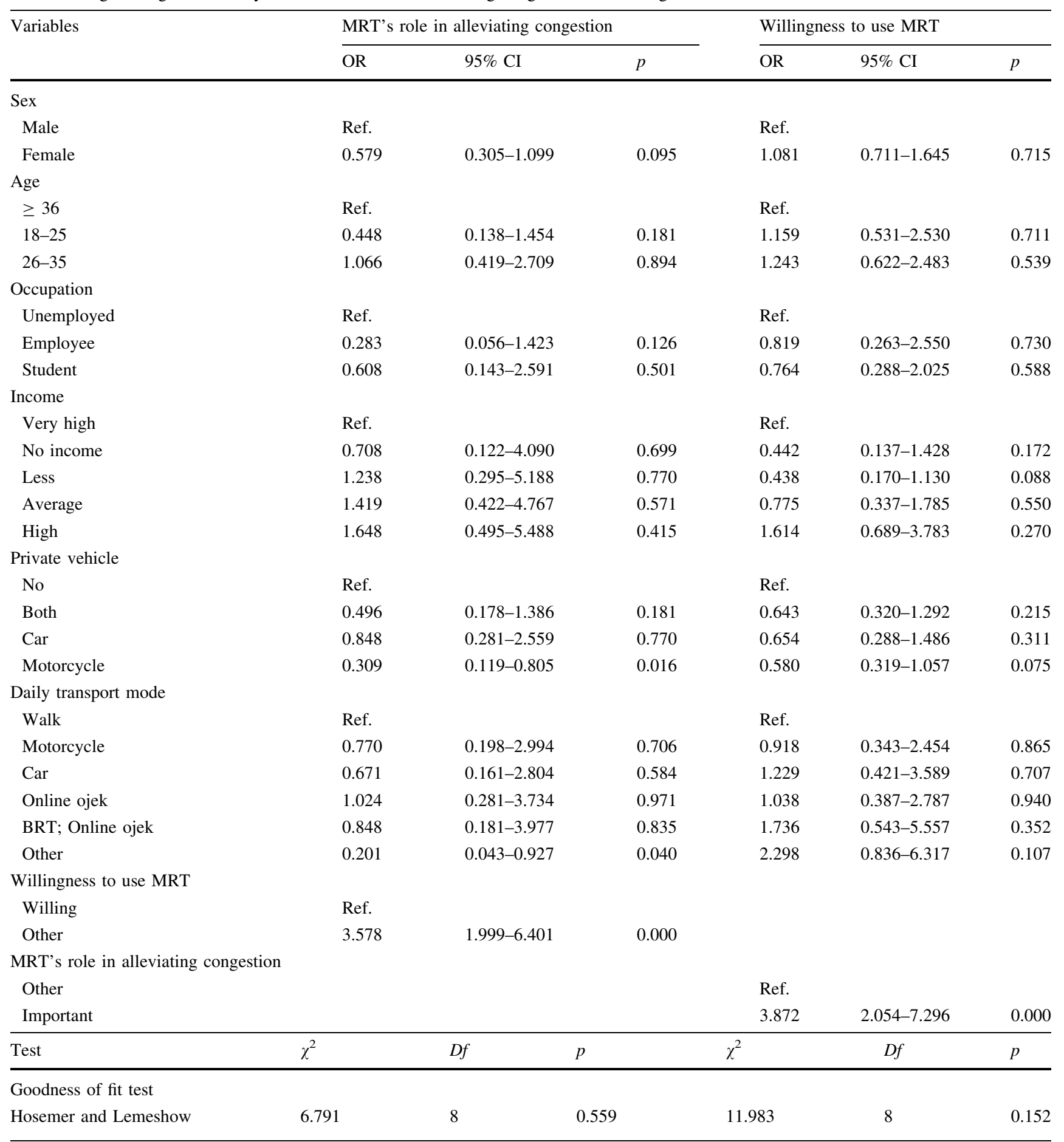

The outcome of MRT's Role in alleviating congestion is 'important (coded 0)' and 'other (coded 1)'. The outcome of willingness to use MRT is 'willing (coded 1)' and 'other (coded 0)'. Code 1 is treated as a reference or effect of cause.

\section{Conclusions and Recommendations}

This paper aimed to reveal public perceptions of Jakarta residents towards a new MRT service, which was launched on 24 March 2019 in Jakarta. Jakarta MRT, inevitably, is currently the most sophisticated inland transport mode in the capital of Indonesia, but prior to its launch, there was no guarantee that the community was willing to use it. Hence, the pre-launch study of a non-operational public transport system investigated people's views on the Jakarta 
Table 5 Description analysis of variables by MRT's role in alleviating congestion and willingness to use MRT

\begin{tabular}{|c|c|c|c|c|}
\hline \multirow[t]{2}{*}{ Variables } & \multicolumn{2}{|c|}{$\begin{array}{l}\text { MRT's role in } \\
\text { alleviating congestion } \\
\text { classification }\end{array}$} & \multicolumn{2}{|c|}{$\begin{array}{l}\text { Willingness to use } \\
\text { MRT }\end{array}$} \\
\hline & $\begin{array}{l}\text { Important } \\
(n: 462)\end{array}$ & $\begin{array}{l}\text { Other } \\
(n: 54)\end{array}$ & $\begin{array}{l}\text { Willing } \\
(n: 342)\end{array}$ & $\begin{array}{l}\text { Other } \\
(n: 174)\end{array}$ \\
\hline \multicolumn{5}{|l|}{ Sex } \\
\hline Female & $279(60 \%)$ & $28(52 \%)$ & $207(61 \%)$ & $100(57 \%)$ \\
\hline Male & $183(40 \%)$ & $26(48 \%)$ & $135(39 \%)$ & $74(43 \%)$ \\
\hline \multicolumn{5}{|l|}{ Age } \\
\hline $18-25$ & $236(52 \%)$ & $22(40 \%)$ & $155(45 \%)$ & $103(60 \%)$ \\
\hline $26-35$ & $164(35 \%)$ & $23(43 \%)$ & $136(40 \%)$ & $51(29 \%)$ \\
\hline$\geq 36$ & $62(13 \%)$ & $9(17 \%)$ & $51(15 \%$ & $20(11 \%)$ \\
\hline \multicolumn{5}{|l|}{ Occupation } \\
\hline Employee & $288(62 \%)$ & $33(60 \%)$ & $233(68 \%)$ & $88(50 \%)$ \\
\hline Student & $152(33 \%)$ & $17(31 \%)$ & $93(27 \%)$ & $76(44 \%)$ \\
\hline Unemployed & $22(5 \%)$ & $4(7 \%)$ & $16(5 \%)$ & $10(6 \%)$ \\
\hline \multicolumn{5}{|l|}{ Income } \\
\hline No income & $151(33 \%)$ & $17(32 \%)$ & $92(27 \%)$ & $76(44 \%)$ \\
\hline Less & $59(13 \%)$ & $8(15 \%)$ & $37(11 \%)$ & $30(17 \%)$ \\
\hline Average & $105(23 \%)$ & $12(22 \%)$ & $81(24 \%)$ & $36(21 \%)$ \\
\hline High & $99(21 \%)$ & $12(22 \%)$ & $91(27 \%)$ & $20(11 \%)$ \\
\hline Very high & $48(10 \%)$ & $5(9 \%)$ & $41(12 \%)$ & $12(7 \%)$ \\
\hline \multicolumn{5}{|l|}{ Private vehicle } \\
\hline Both & $81(18 \%)$ & $8(15 \%)$ & $63(18 \%)$ & $26(15 \%)$ \\
\hline Car & $72(16 \%)$ & $12(22 \%)$ & $56(16 \%)$ & $28(16 \%)$ \\
\hline Motorcycle & $196(42 \%)$ & $15(28 \%)$ & $128(38 \%)$ & $83(48 \%)$ \\
\hline No & $113(24 \%)$ & $19(35 \%)$ & $95(28 \%)$ & $37(21 \%)$ \\
\hline \multicolumn{5}{|l|}{$\begin{array}{l}\text { Daily transport } \\
\text { mode }\end{array}$} \\
\hline Motorcycle & $155(34 \%)$ & $17(32 \%)$ & $96(28 \%)$ & $76(43 \%)$ \\
\hline Car & $78(17 \%)$ & $13(24 \%)$ & $60(17 \%)$ & $31(18 \%)$ \\
\hline Online ojek & $56(12 \%)$ & $11(20 \%)$ & $42(12 \%)$ & $25(14 \%)$ \\
\hline $\begin{array}{l}\text { BRT; online } \\
\text { ojek }\end{array}$ & $32(7 \%)$ & $4(7 \%)$ & $27(8 \%)$ & $9(5 \%)$ \\
\hline Walk & $21(5 \%)$ & $5(9 \%)$ & $15(4 \%)$ & $11(6 \%)$ \\
\hline Other & $120(26 \%)$ & $4(7 \%)$ & $102(30 \%)$ & $22(13 \%)$ \\
\hline \multicolumn{5}{|c|}{ Willingness to use } \\
\hline \multicolumn{5}{|l|}{ MRT } \\
\hline Willing & $321(69 \%)$ & $21(39 \%)$ & - & - \\
\hline Other & $141(31 \%)$ & $33(61 \%)$ & & \\
\hline
\end{tabular}

MRT and their willingness to use it in the future. The case offered unique research which revealed some differences in the views offered by respondents living along the phase 1 MRT corridor and respondents from the other areas of Jakarta. Overall, the overwhelming willingness to use Jakarta MRT identified enthusiasm of the respondents towards this new mode of transport, while the expectations revealed some important aspects and sequence of factors important to the respondents while using the service in the future.

Based on the outcomes of the study, a key policy and operation priority should therefore be to plan for a longterm high standard of Jakarta MRT reliability and security, as the respondents gave these two factors the highest expectations. Moreover, connectivity of Jakarta MRT with other modes of transport should be another priority, which could be achieved by not only adding new MRT routes, but also integrating different modes of transport (e.g. interchanges, transport hubs), introducing information systems (e.g. smart cards), and updating infrastructure (e.g. bridges, station points, pedestrian zones, and pedestrian crossings).

\section{Limitations}

One of the limitations of the study was related to the sampling strategy applied. During the data-collection period, in addition to the online promotion of the survey potential, respondents were also given brochures with Quick Response (QR) code only, so that they could fill out the online survey during leisure times. These potential respondents were targeted at universities, BRT and MRT stations, and office blocks. Overall, a great majority of the respondents in the final sample were young adults, and the participation of adults or elderly in the survey was much lower. This most likely was caused by the fact that adults, especially the elderly, could have had some limitations in accessing the Internet. In the field, they were often busy with work, in a hurry, or felt uncomfortable when approached to complete the survey. It is recognised that these conditions could have made their participation in the study limited.

\section{Next steps}

Considerably more work will need to be done in the future to determine travel preferences of Jakarta and other areas' residents. The willingness section in the survey was only capable of capturing the respondents' views about the MRT, and the section still lacked information related to MRT's competitiveness against other modes. Since the MRT's route is geographically located in the same transport corridor as various other inland transport modes in Jakarta, the issue of how competitive Jakarta MRT really is appears as an intriguing question, which could be explored in further research. 
Open Access This article is distributed under the terms of the Creative Commons Attribution 4.0 International License (http://crea tivecommons.org/licenses/by/4.0/), which permits unrestricted use, distribution, and reproduction in any medium, provided you give appropriate credit to the original author(s) and the source, provide a link to the Creative Commons license, and indicate if changes were made.

\section{References}

1. Badan Pusat Statistik (2017) Population and population growth rate by regency/city in DKI Jakarta Province, 2010, 2014, and 2015

2. Badan Pusat Statistik (2015) Number of registered motor vehicles (Excluding Army, Police and CD) by month and kind of type

3. Mukti I, Prambudia Y (2018) Challenges in governing the digital transportation ecosystem in Jakarta: a research direction in smart city frameworks. Challenges 9(1):14

4. Sitanggang R, Saribanon E (2017) Transportation policies for Jakarta's congestion. Paper presented at the global research on sustainable transport (GROST 2017)

5. PT. MRT Jakarta (2013) Shaping the milestone in Indonesian infrastructure: the first of its kind. In: PT MRT Jakarta

6. Raharjo H (2012) The alternative solution for traffic problem in Jakarta-Indonesia. Int J Bus Manag Stud 1(2):315-320

7. Rukmana D (2018) Rapid urbanization and the need for sustainable transportation policies in Jakarta. Paper presented at the IOP conference series: earth and environmental science

8. Susilo YO et al (2007) A reflection of motorization and public transport in Jakarta metropolitan area. J Eastern Asia Soc Transp Stud 7:299-314

9. JICA (2006) The study on integrated transport master plan for JABOTABEK (Phase I): final report volume III (Review of Jakarta MRT Project) Chapter 5

10. Flyvbjerg B (2005) Measuring inaccuracy in travel demand forecasting: methodological considerations regarding ramp up and sampling. Transp Res Part A Policy Pract 39(6):522-530

11. Dell'Olio L, Ibeas A, Cecin P (2011) The quality of service desired by public transport users. Transp Policy 18(1):217-227

12. Munawar A (2007) Public transport reform in Indonesia, a case study in the city of Yogyakarta. World Acad Sci Eng Technol 28(2007):276

13. Munira S, Sarm S, San Santoso D (2013) Perception of public van users in Bangkok. J Eastern Asia Soc Transp Stud 10:1501-1515

14. Purba A et al (2015) Evaluating Trans Jogja service quality based on user perceptions and expectations. J Eastern Asia Soc Transp Stud 11:1173-1187

15. Tyrinopoulos Y, Antoniou C (2008) Public transit user satisfaction: variability and policy implications. Transp Policy 15(4):260-272

16. Birago D, Mensah SO, Sharma S (2017) Level of service delivery of public transport and mode choice in Accra, Ghana. Transp Res Part F Traffic Psychol Behav 46:284-300
17. Joewono TB, San Santoso D, Susilo YO (2015) Paratransit transport in Indonesia: characteristics and user perceptions. J Eastern Asia Soc Transp Stud 11:1346-1361

18. Sumaedi $S$ et al (2016) Factors influencing public transport passengers' satisfaction: a new model. Manag Environ Qual Int J 27(5):585-597

19. Sumaedi $\mathrm{S}$ et al (2016) The integrated model of theory planned behavior, value, and image for explaining public transport passengers' intention to reuse. Manag Environ Qual Int J 27(2):124-135

20. Nelloh LAM et al (2019) Travel experience on travel satisfaction and loyalty of BRT public transportation. Asian J Technol Manag 12(1): $15-30$

21. Herdiansyah H et al (2019) Supporting factors and factory employee's behaviour in the use of public transportation mode in Jakarta. Transp Probl 14(1):127-139

22. Widjaja A, Astuti W, Manan A (2019) The relationship between customer satisfaction and loyalty: evidence on online transportation services in Indonesia. Ijasre 5(4):214-222

23. Yani TM, Wahyu W, Usman O (2019) The influence of quality of services, prices, locations, loyalty, product design, on the satisfaction transportation customer of Ojek online

24. Belgiawan PF, Schmöcker J-D, Fujii S (2016) Understanding car ownership motivations among Indonesian students. Int J Sustain Transp 10(4):295-307

25. Fraszczyk A, Mulley C (2017) Public perception of and attitude to driverless train: a case study of Sydney, Australia. Urban Rail Transit 3(2):100-111

26. Danapour M et al (2018) Competition between high-speed rail and air transport in Iran: the case of Tehran-Isfahan. Case Stud Transp Policy 6(4):456-461

27. Harvey J et al (2014) Public attitudes to and perceptions of high speed rail in the UK. Transp Policy 36:70-78

28. PT. MRT Jakarta (2017) Sejarah MRT Jakarta. Retrieved from https://www.jakartamrt.co.id/mrt-jakarta/sejarah-mrt-jakarta/

29. De Witte A et al (2013) Linking modal choice to motility: a comprehensive review. Transp Res Part A Policy Pract 49:329-341

30. De Vos J, Ettema D, Witlox F (2019) Effects of changing travel patterns on travel satisfaction: a focus on recently relocated residents. Travel Behav Soc 16:42-49

31. Jain $S$ et al (2014) Identifying public preferences using multicriteria decision making for assessing the shift of urban commuters from private to public transport: a case study of Delhi. Transp Res Part F Traffic Psychol Behav 24:60-70

32. Javid MA et al (2013) Comparison of commuters' satisfaction and preferences with public transport: a case of wagon service in Lahore. Jordan J Civ Eng 7(4):426-472

33. Kumar R (2005) A step-by-step guide for beginners, 2nd edn. SAGE Publications, New Delhi

34. APJII (2016) Fokus Utama saatnya jadi Pokok Perhatian Pemerintah dan Industri. In: Buletin APJII, 05 edn. $p 1$

35. Franke TM, Ho T, Christie CA (2012) The Chi square test: often used and more often misinterpreted. Am J Eval 33(3):448-458 